\title{
Evaluation of the Efficacy of Ultrasound in Detecting Correct Placement of Central Venous Catheter and Determining the Elimination of the Need for Chest Radiography
}

\author{
Suvendu Panda ${ }^{1} \quad$ S.K. Rojalin Baby ${ }^{1}$ Rajesh Thosani ${ }^{1}$ \\ ${ }^{1}$ Department of Cardiac Anesthesia, U.N. Mehta Institute of \\ Cardiology \& Research Centre (UNMICRC), Ahmedabad, Gujarat, \\ India \\ Address for correspondence Suvendu Panda, DM, Department \\ of Cardiac Anesthesia, 3rd Year Resident, U.N. Mehta Institute of \\ Cardiology \& Research Centre (UNMICRC), Ahmedabad, Gujarat, India \\ (e-mail: suvendu00panda@gmail.com).
}

J Card Crit Care:2021;5:18-22

\begin{abstract}
Background and Aims Ultrasound guidance of central venous catheter (CVC) insertion improves the safety and efficacy of its placement, but still it may not ensure correct placement of catheter tip. In our study, we aimed to identify the correct placement of CVC tip and to detect mechanical complications, by visualizing it in real time with the help of sonography and comparing this to the chest $\mathrm{X}$-ray findings.

Patients and Methods This was a cross-sectional observational study conducted on 80 patients with American Society of Anesthesiologists grades 1 and 2, in the age group of 18 to 65 years, who required central venous catheterization in intensive care unit. The CVC tip placement was identified with ultrasound and then the finding was compared with postinsertion chest X-ray.

Results In only 9 out of the 80 patients (11.3\%) malposition was detected on ultrasound and was corrected immediately, whereas in remaining 71 patients (88.8\%) no intervention was required. It was observed that all the patients had correct position of CVC tip on postprocedural chest X-ray. Accidental arterial cannulation occurred in two $(2.5 \%)$ patients in whom right internal jugular vein was cannulated and in two $(2.5 \%)$ patients who had arrhythmia.

Keywords Conclusion Ultrasonography (USG) examination can be used as a diagnostic tool - CVC

- ultrasound

- chest X-ray method for confirmation of CVC tip and identification of cannulation-related complications. Thus, we can say that USG might obviate the need for post-CVC insertion chest X-ray.
\end{abstract}

\section{Introduction}

Central venous access is indicated for hemodynamic monitoring, proper interpretation of central venous pressure, delivery of blood products and drugs in cases of difficult

published online March 18, 2021
DOI https://doi.org/

10.1055/s-0041-1723747 ISSN 2457-0206. peripheral intravenous access, and placement of therapeutic devices.

Central venous catheterization is, however, not without risk and, even in experienced hands, may cause early mechanical complications and misplacements. ${ }^{1}$ Various methods
(C) 2021. Official Publication of The Simulation Society (TSS), accredited
by International Society of Cardiovascular Ultrasound (ISCU).
This is an open access article published by Thieme under the terms of the Creative
Commons Attribution-NonDerivative-NonCommercial-License, permitting copying
and reproduction so long as the original work is given appropriate credit. Contents
may not be used for commercial purposes, or adapted, remixed, transformed or
built upon. (https://creativecommons.org/licenses/by-nc-nd/4.0/)
Thieme Medical and Scientific Publishers Pvt. Ltd., A-12, 2nd Floor,
Sector 2, Noida-201301 UP, India 
such as anatomical landmarks, ${ }^{2,3}$ simple formulae, ${ }^{4}$ Peres formula, radiographic guidance, postinsertion chest X-ray, right atrial electrocardiography, ${ }^{5-7}$ and echocardiography ${ }^{8}$ have been used to ensure correct placement of the central venous catheter (CVC) tip. However, these techniques have their own limitations.

The correct position of the tip of CVC is deemed to be in the superior vena cava above the level of pericardial reflection at the cavoatrial junction. ${ }^{9,10}$ Ultrasound guidance of CVC insertion improves the safety and efficacy of its placement, but still it may not ensure correct placement of catheter tip.

In this study, we aimed to identify the correct placement of CVC tip and to detect mechanical complications, by visualizing it in real time with the help of sonography and comparing this to the chest X-ray findings. The endeavor of this study was to determine whether this technique can eliminate the need for chest X-ray postinsertion of the catheter for reconfirming the correct catheter tip position as is routinely done. Time required for ultrasonography (USG) study and time required from order of chest X-ray to its reporting was also noted.

\section{Methodology}

After obtaining the Institutional Ethical Committee approval, no. 101-20120-142-204632, and taking written informed consent, a cross-sectional observational study was conducted on 80 patients with American Society of Anesthesiologists grade I/II/III, involving patients of both sexes, in the age group of 18 to 65 years, who required central venous catheterization in intensive care unit. Exclusion criteria included: patient's refusal, infection at local site with preexisting chest-tubes, multiple central vein cannulation, traumatic pneumothorax, hemothorax, subcutaneous emphysema, patients with body mass index (BMI) $>40$, altered coagulation profile, arrhythmia, and patients with poor image of cardiac chamber.

In all patients, standard monitors were applied and the patients were kept in supine position-with anesthesiologist at the head end of patient for internal jugular vein (IJV) cannulation or on the ipsilateral side of the patient for subclavian vein (SCV) cannulation, with the ultrasound monitor in view on the opposite side of the bed. The site of cannulation was selected by the anesthetist. Maintaining strict aseptic measures, cannulation of the selected vein was attempted with 7 Fr triple lumen Prymax central vein catheter, $16 \mathrm{~cm}$ in length, by Seldinger technique under ultrasound guidance ( - Fig. 1). Based on studies of Rash Kujur et $\mathrm{al}^{11}$ and Joshi et $\mathrm{al}^{5}{ }^{5}$ catheters were inserted to a length of $13-14 \mathrm{~cm}$ on the right side and to a length of 14 to $15 \mathrm{~cm}$ on the left side. After correct placement of the catheters, each lumen was aspirated and flushed and the triple lumen catheter was secured as recommended.

After cannulation of the selected vein, to ensure correct intravenous placement of catheter tip, $10 \mathrm{MHz}$ linear probe transducer was used to visualize ipsilateral IJV, SCV, and innominate vein for catheter position. Then opposite sides of IJV, SCV, and innominate vein were checked for catheter position. After diagnosis of correct intravenous position,
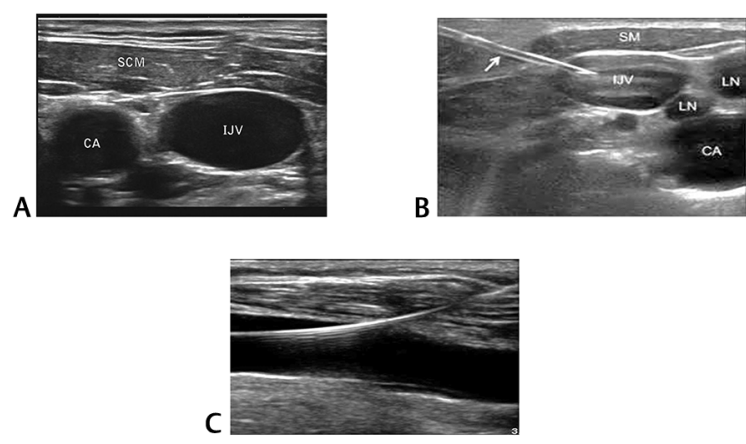

Fig. 1 Ultrasound guided CVC insertion. (A) Short axis view of IJV. (B) Hyperechoic needle within vessel lumen. (C) Long axis view of IJV.
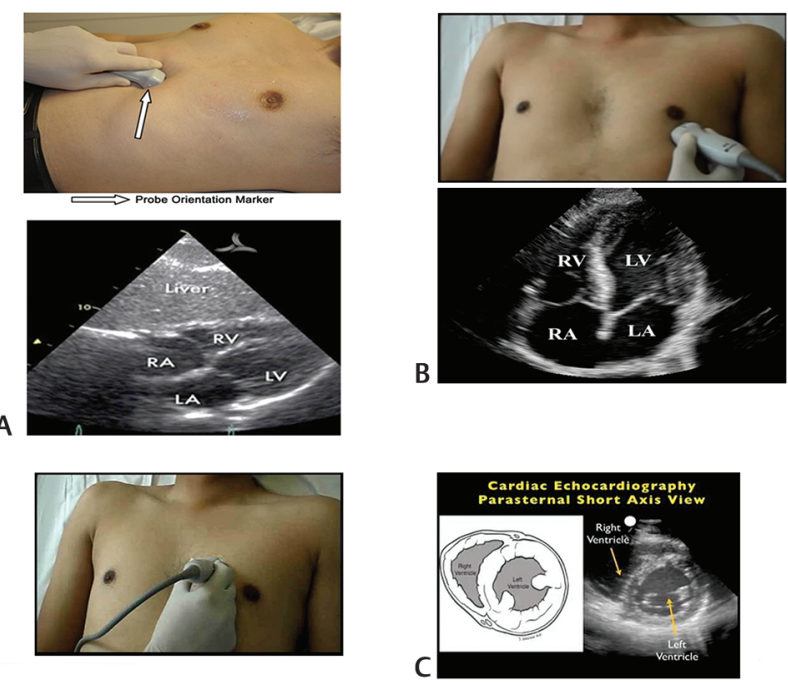

Fig. 2 Transthoracic ecocardiography for catheter tip confirmation. (A) Subcostal view. (B) Apical four chamber view. (C) Parasternal short axis view.

transthoracic echocardiographic (TTE) examination was performed using 3.5 MHz sector probe transducer. Three types of cardiac views were obtained, that is, subcostal view, apical four chamber view, and parasternal short axis view (-Fig. 2). Absence of catheter inside the right atrium was diagnosed as correct placement of CVC tip.

Early mechanical complications related to cannulation, including pneumothorax and hemothorax, were assessed in bilateral thoracic cavities. To detect pneumothorax, $10 \mathrm{MHz}$ linear probe transducer in the anterior intercostal line from third to the fifth intercostal spaces and then laterally in the anterior axillary line was used. Between two ribs, the interface between the thoracic wall and lung is a hyperechogenic line that represents both the visceral and parietal pleura. Comet-tail artifacts are grossly vertical artifacts spreading from the hyperechogenic line to the inferior edge of screen (-Fig. 3). The presence of these artifacts completely ruled out pneumothorax. Lung sliding was searched and its presence in all intercostal spaces was used to rule out postprocedural pneumothorax. In absence of lung sliding in one or more intercostal spaces, the lung point was searched to increase the likelihood of detection of pneumothorax and to 


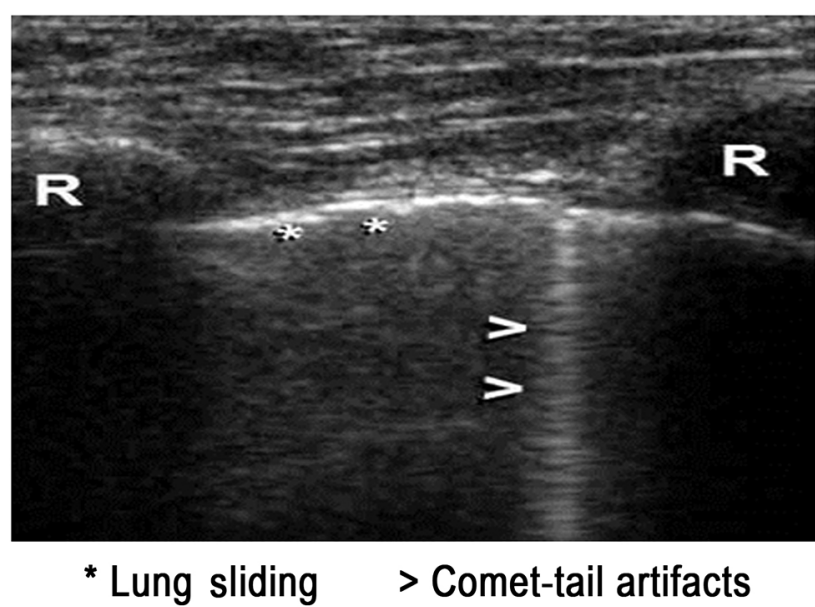

Fig. 3

quantify its extent. To detect hemothorax, 3.5 $\mathrm{MHz}$ sector probe transducer at lateral intercostal space was used.

Post catheter insertion, an expiratory anteroposterior supine position chest X-ray was recorded as a reference for CVC tip placement. CVC tip position was judged as correct, if the tip was positioned just at the level of carina.

Sample size was calculated using the formula for descriptive study $\left.\left(Z^{2} \times p \times q\right) / d^{2}\right)$. With reference to previous study by Matsushima and Frankel in 2010,12 the efficacy of CVC sonography in detection of correct placement in $p=71 \%$ of cases correlated with chest radiography, with precision error of estimation $d=10 \%$ and $\alpha=0.05$, for which a sample size of 80 cases was needed. Descriptive statistics was analyzed with SPSS version 17.0 software. Pearson's chi-squared test or the chi-squared test of association was used to determine if there is a relationship between two categorical variables. Also, $p<0.05$ was considered statistically significant.

\section{Result}

- Table 1 depicts the distribution of various demographic and observational parameters of the group under the study. It was observed that the mean age of distribution was $54.75 \pm 12.83$ years, the mean height of distribution was $161.42 \pm 7.86 \mathrm{~cm}$, the mean weight of distribution was $64.63 \pm 11.37 \mathrm{~kg}$, and the mean BMI of distribution was $24.85 \pm 4.12 \mathrm{~kg} / \mathrm{m}^{2}$.

We observed that the mean central vein insertion length was $13.17 \pm 0.38 \mathrm{~cm}$, mean ultrasound duration was $13.56 \pm 4.98$ minutes, and the average duration from order of chest X-ray to its reporting was $70.3 \pm 3.56$ minutes. It was observed that out of the 80 patients, 2 (2.5\%) had left IJV insertion, 9 (11.3\%) had left SCV insertion, 14 (17.5\%) had right SCV insertion, and the majority patients, that is, 55 (68.5\%), had right IJV insertion. Accidental arterial cannulation occurred in $2(2.5 \%)$ patients in whom right IJV was cannulated and $2(2.5 \%)$ patients had arrhythmia, whereas remaining 78 (97.5\%) patients did not have arrhythmia. In only 9 out of the 80 patients (11.3\%) malposition was detected on ultrasound and was corrected immediately, whereas in remaining 71 patients (88.8\%) no intervention
Table 1 Demographic and observational parameters

\begin{tabular}{|c|c|c|}
\hline \multicolumn{2}{|l|}{ Variable } & Mean $\pm \mathrm{SD} / n(\%)$ \\
\hline \multicolumn{2}{|l|}{ Age $(y)$} & $54.75 \pm 12.83$ \\
\hline \multicolumn{2}{|l|}{ Weight $(\mathrm{kg})$} & $64.63 \pm 11.37$ \\
\hline \multicolumn{2}{|l|}{ Height $(\mathrm{cm})$} & $161.42 \pm 7.86$ \\
\hline \multicolumn{2}{|l|}{ BMI } & $24.85 \pm 4.12$ \\
\hline \multicolumn{2}{|l|}{ CVC insertion length $(\mathrm{cm})$} & $13.17 \pm 0.38$ \\
\hline \multicolumn{2}{|l|}{ USG duration (minutes) } & $13.56 \pm 4.98$ \\
\hline \multicolumn{2}{|c|}{ Order of chest X-ray to reporting (min) } & $70.3 \pm 3.56$ \\
\hline \multicolumn{3}{|l|}{ Insertion site } \\
\hline \multicolumn{2}{|l|}{ Left IJV } & $2(2.5)$ \\
\hline \multicolumn{2}{|l|}{ Left SCV } & $9(11.3)$ \\
\hline \multicolumn{2}{|l|}{ Right IJV } & $55(68.8)$ \\
\hline \multicolumn{2}{|l|}{ Right SCV } & $14(17.5)$ \\
\hline \multirow[t]{2}{*}{ Arterial cannulation } & Yes & $2(2.5)$ \\
\hline & No & $78(97.5)$ \\
\hline \multirow[t]{2}{*}{ Arrythmia } & Yes & $2(2.5)$ \\
\hline & No & $78(97.5)$ \\
\hline \multirow{2}{*}{$\begin{array}{l}\text { Immediate detection and cor- } \\
\text { rection of catheter malposition }\end{array}$} & Yes & $9(11.3)$ \\
\hline & No & $71(88.8)$ \\
\hline \multicolumn{2}{|l|}{$\begin{array}{l}\text { Chest X-ray } \\
\text { (correct position of catheter tip) }\end{array}$} & $80(100)$ \\
\hline
\end{tabular}

Abbreviations: BMI, body mass index; CVC, central venous catheter; IJV, internal jugular vein; SCV, subclavian vein; SD standard deviation; USG, ultrasonography.

was required. It was observed that all the patients had correct position of CVC tip on postprocedural chest X-ray.

- Table 2 depicts distribution of correlation between insertion site and detection by ultrasound and immediate correction of catheter malposition in the group under the study. It was found that $88.9 \%$ of the total malposition was present in right SCV cannulation, $11.1 \%$ of the total malposition was present in left SCV cannulation, while no malposition was detected in IJV cannulation.

\section{Discussion}

Applying safe and effective approaches to vascular catheter insertion should be a priority for all practitioners. ${ }^{13}$ The practice regarding the length of insertion of the CVC has not conformed to any fixed guidelines. ${ }^{14}$ Correct position of CVC is important to avoid life-threatening mechanical complications such as cardiac perforation, cardiac tamponade, dysrhythmias, pneumothorax, and hemothorax.

In our study, all 80 patients had successful central vein cannulation. Central venous cannulation was successful on first attempt in 78 patients, whereas in 2 patients inadvertent carotid artery puncture occurred who underwent IJV cannulation, as IJV was present just anterior to carotid artery. Incidence was statistically insignificant. In a study by Wigmore et $a l,{ }^{15}$ there were three carotid artery punctures in 169 patients in the ultrasound-guided group. There were five carotid artery punctures, one pneumothorax, and four 
Table 2 Correlation between insertion site and immediate detection and correction of catheter malposition by ultrasonography

\begin{tabular}{|l|l|l|l|l|l|}
\hline \multirow{2}{*}{ Insertion site } & \multicolumn{3}{|l|}{ Detection and correction of catheter malposition } & \multirow{2}{*}{$p$-Value } \\
\cline { 2 - 5 } & Yes & No & & \multirow{2}{*}{$<0.001$} \\
\cline { 2 - 5 } & Frequency & $\%$ & Frequency & $\%$ & \\
\hline Left IJV & 0 & 0.0 & 2 & 2.8 & 11.3 \\
\hline Left SCV & 1 & 11.1 & 8 & 77.5 & \\
\hline Right IJV & 0 & 0.0 & 55 & 100 & \\
\hline Right SCV & 8 & 88.9 & 6 & & \\
\hline Total & 9 & 100 & 71 & & \\
\hline
\end{tabular}

Abbreviations: IJV, internal jugular vein; SCV, subclavian vein.

hematomas in 115 patients in the landmark group. There was a significantly greater number of failed insertions in the landmark technique group ( $7 / 115$ vs $1 / 169 ; p=0.01)$. They observed an absolute risk reduction in favor of USG of $6.9 \%{ }^{15}$ In a study by Brass et $\mathrm{al}^{16}$ for $\mathrm{IJV}$, the number of attempts needed for successful cannulation decreased in all subgroups. Use of ultrasound increased the chance of success at the first attempt by $57 \%$. For the SCV, ultrasound reduced the risk of inadvertent arterial puncture. ${ }^{16}$ Based on above data we concluded that two-dimensional ultrasound offers increased safety when compared with anatomical landmark technique.

In our study, aberrant catheter position occurred in nine cases. All of the malposition was with SCV cannulation. In 14 cases right subclavian catheter was inserted, of which in 8 cases guide wire tip was detected in the ipsilateral IJV on table, and in 9 patients in whom left SCV catheter was inserted, guide wire tip was detected in the ipsilateral IJV in 1 case. No malposition was detected during IJV cannulation. These malpositions were corrected and intracardiac catheter tip position was ruled out by TTE and later by chest X-ray $(p<0.001)$.

Maury et $\mathrm{al}^{17}$ evaluated ultrasonic examination as a diagnostic tool for catheter misplacement after CVC insertion. Eighty-five CVCs were inserted into 81 patients; 10 misplacements occurred. All misplacements except one were diagnosed by ultrasound, but they did not correct the misplacement under ultrasound guidance. Postprocedural chest radiography also disclosed 10 misplacements. They concluded that ultrasonic examination is accurate in detecting catheter misplacement after SCV and IJV cannulation. ${ }^{17}$

Matsushima and Frankel $^{12}$ conducted a prospective study to evaluate the efficacy of novel CVC sono-technique for identifying the CVC insertion related, or peripherally inserted central catheter related, complications and to eliminate the need for postinsertion chest radiography. The positive predictive value of CVC sonography was $83 \%$ and negative predictive value was $91 \%$. Based on the above data, our study corroborated with the study by Matsushima and Frankel. ${ }^{12}$

In our study, no pneumothorax or hemothorax occurred after central venous cannulation observed with USG and postoperative chest X-ray. Only two patients had arrythmia, which was statistically insignificant $(p=0.818)$.
In our study, entire time required to perform ultrasonic examination was $13.56 \pm 4.98$ minutes, and catheter confirmation time by chest radiography was $70.3 \pm 3.56$ minutes. No discrepancy existed between sonographic and radiographic confirmation of catheter placement. In a study by Maury et al, the entire time required to perform ultrasonic examination was $6.8 \pm 3.5$ minutes, whereas it took $80.3 \pm$ 66.7 minutes for the chest radiography $(p<0.0001) .{ }^{17}$ In a study by Matsushima and Frankel, mean examination time for CVC sonography was 10.8 minutes, which was significantly shorter than the time required to obtain the chest radiograph, which was 75.3 minutes $(p<0.001) .{ }^{12}$

\section{Conclusion}

In our study, we could collaborate USG confirmation of CVC tip with postprocedural chest X-ray findings, but we could not collaborate pneumothorax and hemothorax as there was no incidence of these complications. Thus, we can say that USG might obviate the need for postoperative chest X-ray.

\section{Financial Support and Sponsorship \\ Nil.}

\section{Conflicts of Interest}

There are no conflicts of interest.

\section{References}

1 Schummer W, Schummer C, Rose N, Niesen WD, Sakka SG. Mechanical complications and malpositions of central venous cannulations by experienced operators. A prospective study of 1794 catheterizations in critically ill patients. Intensive Care Med 2007;33(6):1055-1059

2 Ryu HG, Bahk JH, Kim JT, Lee JH. Bedside prediction of the central venous catheter insertion depth. $\mathrm{Br} \mathrm{J}$ Anaesth 2007;98(2):225-227

3 Ezri T, Weisenberg M, Sessler DI, et al. Correct depth of insertion of right internal jugular central venous catheters based on external landmarks: avoiding the right atrium. J Cardiothorac Vasc Anesth 2007;21(4):497-501

4 Czepizak CA, O'Callaghan JM, Venus B. Evaluation of formulas for optimal positioning of central venous catheters. Chest 1995;107(6):1662-1664

5 Joshi AM, Bhosale GP, Parikh GP, Shah VR. Optimal positioning of right-sided internal jugular venous catheters: comparison of intra-atrial electrocardiography versus Peres' formula. Indian J Crit Care Med 2008;12(1):10-14 
6 Gebhard RE, Szmuk P, Pivalizza EG, Melnikov V, Vogt C, Warters RD. The accuracy of electrocardiogram-controlled central line placement. Anesth Analg 2007;104(1):65-70

7 Watters VA, Grant JP. Use of electrocardiogram to position right atrial catheters during surgery. Ann Surg 1997;225(2):165-171

8 Jeon Y, Ryu HG, Yoon SZ, Kim JH, Bahk JH. Transesophageal echocardiographic evaluation of ECG-guided central venous catheter placement. Can J Anaesth 2006;53(10):978-983

9 Sivasubramaniam S, Hiremath M. Central venous catheter: do we need to review practice on positioning? J Intensive Care Soc 2008;9:228-231

10 Stonelake PA, Bodenham AR. The carina as a radiological landmark for central venous catheter tip position. Br J Anaesth 2006;96(3):335-340

11 Kujur R, Rao S. M., Mrinal M. How correct is the correct length for central venous catheter insertion. Indian J Crit Care Med 2009;13(3):159-162

12 Matsushima K, Frankel HL. Bedside ultrasound can safely eliminate the need for chest radiographs after central venous catheter placement: CVC sono in the surgical ICU (SICU). J Surg Res 2010;163(1):155-161
13 Bodenham Chair A, Babu S, Bennett J, Binks R, et al. Association of anaesthetists of Great Britain and Ireland: safe vascular access 2016. Anaesthesia 2016;71(5):573:585

14 Fletcher SJ, Bodenham AR. Safe placement of central venous catheters: where should the tip of the catheter lie. ? $\mathrm{Br}$ J Anaesth 2000;85(2):188-191

15 Wigmore TJ, Smythe JF, Hacking MB, Raobaikady R, MacCallum NS. Effect of the implementation of NICE guidelines for ultrasound guidance on the complication rates associated with central venous catheter placement in patients presenting for routine surgery in a tertiary referral centre. $\mathrm{Br}$ J Anaesth 2007;99(5):662-665

16 Brass P, Hellmich M, Kolodziej L, Schick G, Smith AF. Ultrasound guidance versus anatomical landmarks for internal jugular vein catheterization. Cochrane Database Syst Rev 2015;1:CD006962

17 Maury E, Guglielminotti J, Alzieu M, Guidet B, Offenstadt G. Ultrasonic examination: an alternative to chest radiography after central venous catheter insertion? Am J Respir Crit Care Med 2001;164(3):403-405 